\title{
Essay
}

\section{Positive Creativity Is Principled Creativity}

\author{
Ronald A. Beghetto ${ }^{1, *}$ and Ross C. Anderson ${ }^{2}$ \\ 1 Mary Lou Fulton Teachers College, Arizona State University, Tempe, AZ 85281, USA \\ 2 Inflexion, Eugene, OR 97401, USA; ross.anderson@inflexion.org \\ * Correspondence: ronald.beghetto@asu.edu
}

check for

updates

Citation: Beghetto, R.A.; Anderson, R.C. Positive Creativity Is Principled Creativity. Educ. Sci. 2022, 12, 184.

https://doi.org/10.3390/

educsci12030184

Academic Editors: Robert

J. Sternberg and Sareh Karami

Received: 31 January 2022

Accepted: 3 March 2022

Published: 6 March 2022

Publisher's Note: MDPI stays neutral with regard to jurisdictional claims in published maps and institutional affiliations.

Copyright: (C) 2022 by the authors. Licensee MDPI, Basel, Switzerland. This article is an open access article distributed under the terms and conditions of the Creative Commons Attribution (CC BY) license (https:// creativecommons.org/licenses/by/ $4.0 /)$.

\begin{abstract}
The purpose of this article is to introduce an action-oriented framework aimed at clarifying and promoting a principled approach to creativity in education. A principled approach to creativity refers to the design and implementation of positive creative educational endeavors, which are guided by a set of agreed-upon commitments aimed at making a positive contribution to the learning and lives of others. We open by discussing how our conception of a principled approach to creativity connects to positive creativity and how this approach can guide creative educational endeavors. More specifically, we discuss the opportunities and responsibilities associated with a principled approach to creativity, including how educators, students, and researchers can re-conceptualize creative opportunities, creative risk-taking, creative action, and the intended and unintended outcomes that result from promoting creative thought and action in and beyond the walls of schools and classrooms.
\end{abstract}

Keywords: creativity; positive education; positive creativity; positive psychology in schools; principled creativity

\section{Positive Creativity Is Principled Creativity}

We assert that positive creativity is principled creativity. In making this claim, we must first outline what is meant by positive creativity. Our understanding of positive creativity aligns with the conception offered by Sternberg and Chowkase [1], which describes positive creativity as representing novel and meaningful actions and outcomes that, in some way, make the world a better place. We also agree with Sternberg and Chowkase [1] that this seemingly simple definition of positive creativity belies a deeper level of complexity, particularly when considered within an educational context.

Indeed, the complexity of the concept of positive creativity quickly emerges when we start to consider the design and enactment of positive creative educational experiences in and beyond the walls of schools and classrooms. How, for instance, might educators and young people identify the kinds of creative educational opportunities that are worth pursuing? What kinds of risks are associated with such endeavors, and how can educators and young people appraise those risks? What guides educators' and young peoples' actions when engaging in creative educational opportunities? How might the outcomes, both intended and unintended, of those creative actions be anticipated, evaluated, and addressed? What sociocultural value systems are used to weigh the potential positive and negative outcomes of certain creative endeavors?

In this article, we aim to address these questions. More specifically, we assert that these questions point to a deeper feature of positive creativity that we call principled creativity. Principled creativity refers here to the design and implementation of positive creative educational endeavors that are guided by a set of agreed-upon commitments aimed at making a positive contribution to the learning and lives of others. A principled approach to creativity thereby underscores a shared responsibility amongst educators and young people to continuously clarify and systematically monitor the ethical dimensions of creative engagement in education. The clarification and systematically monitoring of principled dimensions can include a range of questions, including: Does this creative endeavor 
support (or inadvertently) suppress the creative agency of everyone involved?; What are the potential local or societal benefits and drawbacks of engaging in this creative learning experience?; and Does this creative learning experience help to democratize education or further disenfranchise historically marginalized students and families?

It is important to note, at the outset of this article, that a principled approach to creativity requires learning how to strike a productive balance between systematically evaluating creative outcomes and the willingness to take creative risks. This balance is important because researchers have documented how preoccupation with outcomes and external evaluations can disrupt the creative process [2], undermine creative engagement [3,4], and ultimately interrupt the motivational focus [5] and creative risk-taking [6] necessary for producing creative outcomes (We want to thank one of the reviewers of this article for noting the dynamic tension that exists between monitoring outcomes and creative risk-taking). In this way, a principled approach to creativity in education involves the active shifting of focus between creative engagement and the monitoring of outcomes at multiple levels (e.g., the experience of the individual learner and teacher, the classroom or school as a community, and the world-at-large). Consequently, one key skill that young people can develop in creative educational endeavors is learning how to regulate their focus. Indeed, accomplished creators know how to monitor potential unintended consequences without disrupting their engagement and the risk-taking necessary for creative work.

In the sections that follow, we discuss how a principled approach to creativity builds on and compliments similar efforts and initiatives [1,7-9]. A principled approach to creativity also represents a more specific feature of broader efforts in positive education and positive psychology in schools. Principled creativity, for instance, compliments allied work in positive education because efforts aimed at cultivating a principled approach to creativity engage students in creative learning experiences that can contribute to the learning and wellbeing of themselves and others $[10,11]$. Principled creativity is also aligned with broader efforts in positive psychology in schools because a principled approach to creativity helps to facilitate student agency and promote productive school engagement [12].

In what follows, we discuss how a principled approach to creativity operates within a broader agentic approach for guiding positive creative educational endeavors. More specifically, we discuss the opportunities and responsibilities associated with principled creativity, including how educators, students, and researchers can re-conceptualize creative opportunities, creative risk-taking, creative action, and the intended and unintended outcomes that result from promoting creative thought and action in and beyond the walls of schools and classrooms.

\section{A Principled Approach to Creativity}

We assert that a principled approach to creativity represents agentic action $[13,14]$, meaning that it requires the willingness and ongoing action necessary to identify, implement, and monitor the intended and unintended consequences of positive creative experiences in education. Figure 1 depicts the various components of an agentic approach for guiding principled creative educational endeavors. Prior to discussing the components, we first want to discuss how a principled approach to creativity emerges from the concerns that many educators and educational leaders have when introducing new concepts, policies, practices, and pedagogical approaches in schools and classrooms.

Given the increased emphasis placed on creativity in educational settings, researchers and educators have started to examine how creativity might complement and enhance the educational experience. As has been noted more broadly, creativity is an oftenmisunderstood concept in educational contexts $[15,16]$, and many educators are ambivalent about whether and how creativity might support their core responsibility of teaching academic subject matter [17]. Even when educators are equipped with research-based definitional criteria for creativity (i.e., some blend of originality and usefulness) and see the value in supporting young people's creative expression [18], they may still struggle to integrate creativity into the classroom. Educators sometimes struggle with supporting 
creative expression in the curriculum because their primary professional responsibility is to ensure the academic learning of students [19] and they may worry that the creative expression of students [20] will disrupt (rather than support) classroom learning.

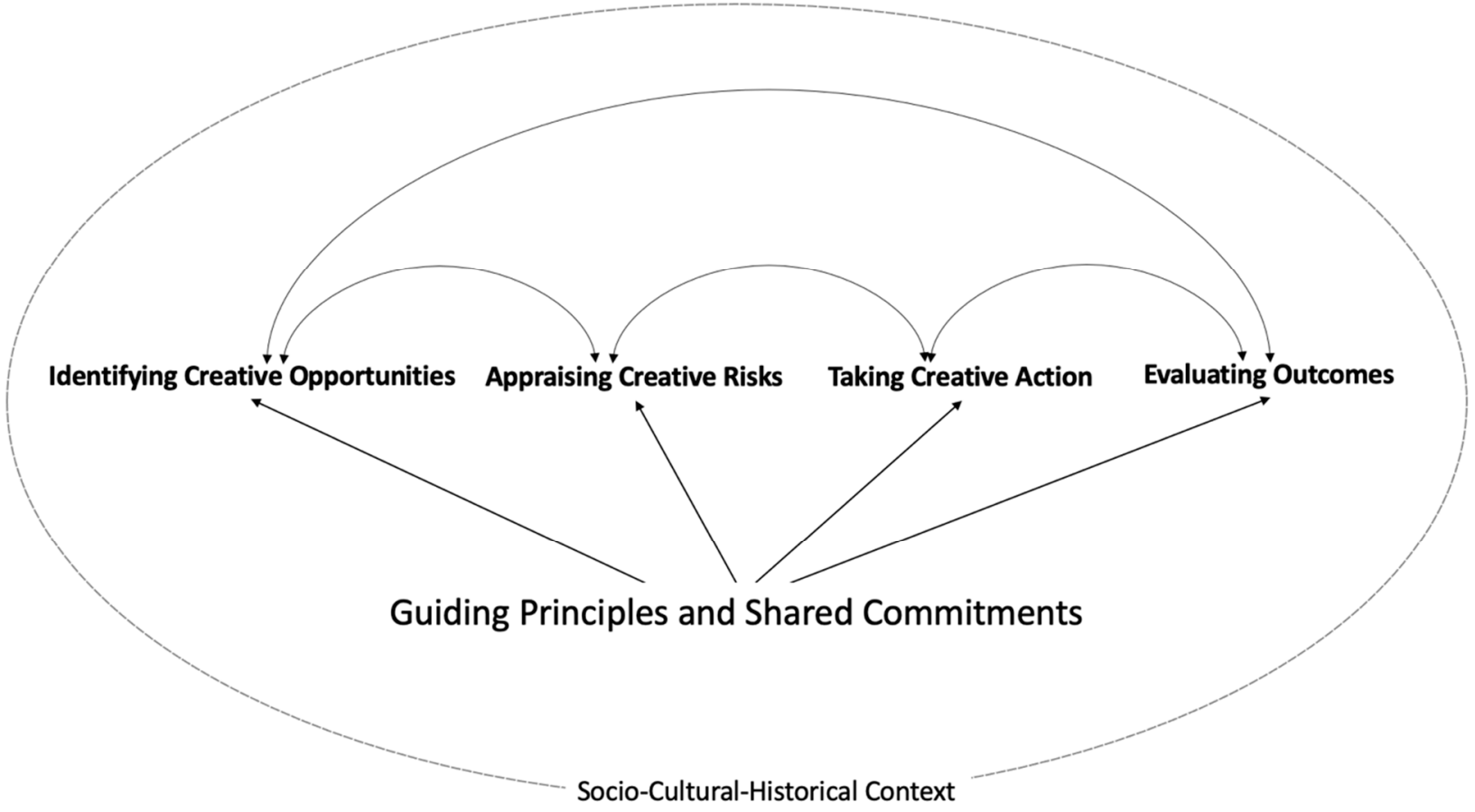

Figure 1. Shared commitments and responsibilities of principled creativity.

The concept of principled creativity can help clarify how infusing creative educational experiences in the classroom can complement (rather than compete with) teachers existing curricular commitments and responsibilities. This is because a principled approach to creativity provides students with opportunities to put their academic learning into creative work in ways that positively contribute to the learning and lives of others. It is from this perspective that we introduce the approach depicted in Figure 1.

\section{Introducing an Agentic Approach to Principled Creativity}

Our agentic approach to principled creativity operates from a set of assumptions, which have a basis in the recognition that any principled creative effort will involve an assemblage of intentions, decisions, responsibilities, actions, and ongoing appraisals. In the context of principled creativity, taking creative action carries the added responsibility of attempting to ensure that creative efforts result in positive (rather than detrimental) creative outcomes for oneself and others. These responsibilities include identifying creative opportunities, appraising creative risks, taking creative action, and systematically evaluating outcomes (see Figure 1). Each of these responsibilities is discussed in the sections that follow.

In discussing the components of our approach, we also feel it important to highlight two interrelated features of a principled approach. The first underscores the principled aspect of principled creativity, and the second highlights the central role played by context (see Figure 1). More specifically, the responsibilities associated with engaging in principled creative endeavors are informed by guiding principles and shared commitments, as defined within a particular sociocultural and historical context. In this way, the principles and commitments do not emerge from "nowhere in particular" [21] but rather rely on an agentic process of clarifying the principles and commitments guiding creative endeavors in relation to the sociocultural and historical context.

In education, these principles are informed by the social and cultural values of students, students' families, and teachers to avoid propagating overly narrow and exclusionary 
approaches that privilege pedagogies of sameness and, instead, move us toward pedagogies of the possible [22]. Pedagogies of the possible recognize the importance of difference and actively provide support for creative action of students, families, and community members who have been historically marginalized in and out of school [23-25]. Creative engagement in learning has great potential to be culturally responsive and sustaining for students [26], especially as a way to build strong relationships and make space for meaningful creative expression. It is in those relationships that teachers and young people can develop a shared commitment aimed at learning from and actively engaging with different ways of cultural knowing, values, and perspectives [27].

A principled approach to creativity thereby incorporates perspectives on culturally situated, responsive, and sustainable approaches to teaching and learning. History teaches us that exclusionary creative practices in schools can be harmful to the most vulnerable and marginalized students in a classroom because such practices reinforce dominant and often oppressive cultural narratives and norms. For example, if teachers are unaware of the value of hip hop as a richly meaningful and sophisticated cultural form of creative expression in English language arts [28], its potential for positive creativity in the classroom will likely be ignored or, even worse, referred to as destructive and harmful. Creative educational experiences that, for instance, center on the lived reality and culture of diverse communities can have a rich and profoundly important contribution to the healthy identity development and creative expression of young people [23-25,29]. Ensuring all students feel their culture and ideas are welcome fosters a sense of belonging [30], which can counteract the historical marginalization of culturally, linguistically, racially, and ethnically minoritized students. From this perspective, creative educational experiences can democratize creativity in schools by instantiating the full spectrum of student identities and culturally valued ways of knowing.

The principles, commitments, values, and kinds of experiences that guide creative educational efforts result from ongoing consideration and dialogue amongst a plurality of perspectives in a given educational context. Consequently, the principles and commitments in one educational context during one time may (and likely will) differ across different educational and temporal contexts. We thereby assert that the design of any creative educational experience starts with clarifying the guiding principles and shared commitments relevant to the context and then establishing a plan for monitoring and acting on these principles and commitments.

Having briefly outlined the principled and contextual features of our approach, we can now turn our discussion to each of the four responsibilities. Within each responsibility, at least four audiences should be considered, with different degrees of proximity to the positive and negative effects of the creative experience: (a) individual students; (b) teachers; (c) broader members of the classroom and school community; and (d) the world outside the classroom and school.

\section{Responsibility \#1: Identifying Creative Opportunities}

Identifying creative opportunities is a critically important responsibility of any positive creative educational endeavor. Indeed, "problem finding" or "problem identification" is one of the distinctive features of creative work and distinguishes it from routine problemsolving [31-33]. Creative learning opportunities can range from intensive, long-term experiences to routine daily interactions and engagements [34]. Given that identifying largescale opportunities may initially feel daunting to teachers, smaller-scale efforts serve as an ideal and effective starting point. One example of an effective, smaller-scale effort is the makeSPACE project [15]. This project engages teachers in the process of identifying smallerscale creative and artistic routines that can serve as the basis of developing meaningful creative experiences in their classrooms. The process starts with teachers taking small steps, such as addressing the following questions:

- What routines do I engage students in on a regular basis?

- How can these routines become opportunities for creative learning and expression? 
- How can these routines offer the students opportunities to express themselves?

- How can I ensure these creative opportunities develop a classroom culture of creative risk-taking?

- How can I safeguard the most vulnerable students to ensure they feel safe to engage and share their unique perspectives?

Research on this small-scale approach has demonstrated that teachers who engaged in this process increased their sense of belonging, autonomy, competency, and creative possibility in their professional work [15]. Moreover, as teachers develop their confidence in the creative problem-finding process, they are more prepared to carry these practices into their own classrooms. When this happens, students learn that creative problem finding differs from the prototypical educational experience, whereby educators and curricula designers predetermine almost every feature of the learning experience [34]. Specifically, teachers provide students with the opportunity to identify their own problems to solve and their own way of solving them. This is facilitated by teachers establishing a supportive and structured learning environment so as not to overwhelm students. In this way, students learn how to work creatively within constraints in a supportive and structured setting that affirms students' voices, values, perspectives, and concerns.

Problem identification guidelines, such as the design questions of a legacy project [35], can be helpful in providing structure for students' creative exploration. More specifically, legacy projects invite young people to work with members of their broader community to identify problems worth solving that can make a positive and lasting contribution to the learning and lives of others. The following design questions of legacy projects can help young people and educators identify creative endeavors guided by principles and shared commitments:

- What is the problem? This question prompts students to engage in problem finding and identify an issue, challenge, or concern that matters to them and members of their school or the broader community. It can be a problem that perhaps no one else sees or realizes is a problem.

- Why does it matter? This question encourages students to think about the problem from a principled stance by inviting them to consider who the problem impacts, clarify how they know it is a problem, consider what will happen if nothing is done about the problem, and clarify their rationale for why this problem is worth solving and why they are committed to doing something about it.

- What are we going to do about it? This question underscores the agentic aspect of the process by asserting that engaging in principled creative endeavors goes beyond identifying, naming, and clarifying problems and towards accepting the responsibility to take creative action. The question also prompts students to consider what is needed to take action, who the students can partner with to assist them in addressing the problem, and what first steps they will take.

- How will we ensure that we make a lasting and positive contribution to others? This final question forefronts the principled aspect of creative endeavors. Specifically, this question invites young people to consider from the outset how the actions they plan to take align with their shared commitments and values. Addressing this question will also require that students establish and implement a plan to monitor and address unintended consequences to help ensure that they are making a positive contribution.

The above design questions, and prompts like them, can serve as a launchpad for a wide range of principled creative experiences in education. In this way, legacy projects can direct students' creative attention to the potential impact on the school community and the world at large.

Consider, for instance, a group of middle school science teachers who want to develop a creative learning project for their students. The teachers and students live in a droughtprone state. The teachers start the process by doing their own creative problem-finding to find creative ways to engage students in scientific models of the water cycle to deepen students' understanding of chronic drought in their state and region. As students learn 
about the intensity of drought in their region and the effects on their own community, they might also be tasked with identifying a problem related to drought that they can address. Students might first be asked to design and create their own microclimate in a terrarium in the classroom with a heat lamp and mist sprayer to simulate what happens in a drought and how different kinds of plants respond. Next, students could then be expected to identify and research a specific drought-related problem in their community. Students would then be asked to generate potentially creative solutions to the local problem and work in teams to design different solutions, thinking through the possible intended and unintended consequences. As part of this process, students would be expected to seek feedback on their ideas from relevant experts and ultimately propose a plan to school leadership for planting drought-tolerant trees on school grounds alongside a future school garden to offer shade to planted fruits and vegetables. Following a principled approach to creativity, the students would also develop a plan for monitoring the intended and unintended consequences of drought-tolerant tree planting on school grounds and then take the actions necessary to implement the project.

This kind of creative learning opportunity combines academic learning with principled problem-finding. Principled problem-finding aligns with the empathy-building process in design thinking for education, where teachers and students learn as much as they can about the context, values, and core features of an issue or problem [36]. As Sternberg and Chowcase [1] emphasize, developing empathy and compassion through regular exercises is just as important to positive creativity in education as developing the creative and critical thinking skills that lead to novel and effective ideas and actions.

\section{Responsibility \#2: Appraising Creative Risks}

Risk-taking is an inherent part of the creative process, and uncertainty is a necessary ingredient because creativity is defined by the unknown and the possible. Uncertainty describes a state of doubt, of not knowing, and a lack of predictability and control over what to expect. In teachers and students, uncertainty exists on a spectrum of intensity [37], from the mundane faced in everyday teaching and learning (e.g., "Will this new lesson go well?") to profound uncertainties, which feel entirely unknowable (e.g., "Will the COVID-19 pandemic ever end?"). Between those extremes resides actionable uncertainty where creative opportunities become possible. Principled creativity requires assessing the degree of uncertainty, level of risk, and management of strong emotions, such as fear and anxiety, as well as the potential costs and benefits of a new idea or action. Scaffolding the uncertainty and level of risk in creative learning is key to building the agentic beliefs that translate to creative action. In a principled approach, teachers hold the responsibility to make this scaffolding successful for students, modeling risk-taking themselves and monitoring and adjusting as they go. Similarly, students hold the responsibility to support one another in creative risk-taking, sharing in the vulnerability of not knowing how things will go.

An example of a risk that teachers need to navigate is whether the creative learning opportunities they provide for students might inadvertently exclude some students. From a principled approach, teachers would need to weigh the risk of implementing seemingly beneficial creative learning opportunities against the potential hazard that such opportunities may not be accessible to all students. Drawing from Rose's [38] work on universal design for learning as well as work on anticipating unintended consequences [39], the following planning questions can be helpful for teachers and researchers when attempting to address the risk of excluding students when planning creative curricular experiences:

- How can I offer students multiple modalities and means to engage in content and learning?

- How am I ensuring that all students have different ways to access subject matter content necessary for understanding and engaging with this activity?

- How might I offer students multiple ways to express, demonstrate, and communicate their thinking and learning? 
- Who can I discuss this curricular experience with to help me be aware of any potential issues that I might be missing with respect to student access and modifications I might make to ensure that this is accessible and feasible for all students?

- Prior to and during the implementation of this curricular experience, how might I invite students to share any concerns or challenges they anticipate or experience so that we can make timely modifications and accommodations?

Using the above planning questions as a guide, teachers and researchers would be in a better position to anticipate and proactively address issues of access when developing a creative learning experience. Consider, for instance, a teacher who has developed a creative activity that heavily relies on mastery of the English language. Working through the above questions, the teacher would be more likely to realize how such an activity might exclude students whose home language is not English or who are still in the process of learning the English language. In such cases, teachers who use principled creative planning questions, such as those listed above, might modify their plan to include drama-based techniques, which can better accommodate all students by enabling opportunities and strategies to communicate their ideas and experiences through creative gesture and physical enactment (rather than relying on written or spoken English). Doing so is just one example of how principled creative planning can help level the playing field of classroom participation.

Principled creative planning can also anticipate and help teachers navigate the risk of students or themselves being limited by counter-productive creativity myths (e.g., "creative experiences should only be used in the arts") and paradigms (e.g., "only highly gifted students can be creative"). A principled approach to creative learning recognizes that students and teachers, themselves, might hold internally conflicting beliefs about creativity, such as whether creative abilities are fixed or can develop with effort $[17,40,41]$. Without principled planning, teachers may inadvertently pass on problematic implicit theories [42] about creative ability to students with messaging that seems supportive but can actually suppress creative expression, such as "It's okay if you're struggling, not everyone can solve math problems creatively." Teachers' messaging and modeling are powerful levers to support students' accurate appraisal of internal and external risks, including the risk of confirming self-limiting beliefs about the nature of creative potential.

From a principled approach to creativity in the classroom, students learn how to monitor their creative actions through the active and ongoing appraisal of whether the potential benefits associated with being creative are worth the effort and the potential hazards, given the specific circumstances. In some cases, students' creative choices may have a negative effect on themselves, their teachers, their peers, or other people around them. Indeed, novelty may not always be welcomed [43] or even useful and safe (e.g., a student deciding to ignore lab safety rules during a chemistry class because the student believes those rules are "stifling their creativity").

When creativity does fit the situation or context, however, students need to consider which strategies will fit better than others. This internal process draws on students' creative metacognition, which plays a key role in reading the situation [44] and regulating their creative behaviors and emotions [45] to ensure that the resulting contribution of their creative ideas and actions are beneficial. Along these lines, researchers and educators can support students learning that all creative expression involves some level of risk. Students learn how to weigh the intended and unintended consequences of their creative actions to determine whether the risks they plan fall into one of three categories [34]: good risks (i.e., the potential benefits to oneself outweigh the hazards), bad risks (i.e., the hazards to oneself or others outweigh the potential benefits), or beautiful risks (i.e., the potential longterm benefits to others outweigh the potential hazards). Principled creative experiences in education aspire to encourage teachers and young people to take beautiful risks.

Indeed, a principled creative approach provides a layer of consideration to help students and educators in identifying problems worth addressing as well as anticipate and consider potential short- and long-term benefits and hazards for future students and community members. Whereas the problem-finding and idea-generation phase calls for 
what if curiosity, the appraisal of risk calls for so what questioning and if-then considerations of impact. As noted at the outset of this article, learning how to regulate one's focus so as to strike a balance between appraising risks and still being willing to engage in creative endeavors that are worthwhile is a skill that accomplished creators possess. Students, therefore, need support and encouragement to learn when to focus on outcomes and when to focus on creative endeavors. Otherwise, students may not be willing to take creative risks when it is necessary to do so.

Here is an example of how a principled creative approach can help support students risk appraisal to ensure they are making a positive creative contribution. Imagine a group of middle school students engaged in a "real-world" creative problem-solving project aimed at identifying and addressing a local challenge or problem that they will attempt to address creatively. In the "what if" problem identification phase, a principled creative approach would require students to think beyond themselves and identify problems and challenges of people in their local community that they (or others) may not realize is a problem. Through the process of discussions with people in their school and community, students realize that there is a "food desert" very close to their school, in which families have limited access to fresh produce. They realize that starting a garden on school property, for instance, could be a beneficial solution to this problem. The students may be very eager and excited to implement their idea, given that it has been endorsed by the school and supported by donations from the local gardening company.

A principled approach would pause the implementation process until risks can be assessed. Pausing implementation ensures that the students do not rush forward without also developing a plan that will ensure that the garden can be maintained and successfully contribute to the community. These more complex features might, for instance, include: (a) developing a sustainable and effective delivery plan for families (e.g., making sure the produce they grow gets to people in need), (b) developing a use monitoring plan (e.g., keeping track of actual use to ensure that they are meeting demand, have the ability to bring the gardens to scale by including other locations, and avoid waste from overproduction), and (c) establish a succession and evaluation plan (e.g., involving younger students and community members to ensure that the project carries on when the initial group of students leaves for high school; determining the success of the actual garden with respect to meeting the need). Once students have worked through this appraisal and planning process, they would then need to be encouraged to move forward and implement the project.

Actively appraising creative risks is akin to the idea of appropriate technology [46]. When a new technology is implemented in a specific community, it is important to make sure it can be self-sustaining in that it can be used, maintained, monitored, and repaired by members of the community, with limited need to rely on outside experts. The creative engineering that emerged from the Gaviotas community in Columbia, for example, led to sustainable water pumps in isolated locales that were bike- and seesaw-powered and located within community centers [46]. A principled approach to creativity reminds us that the potential and actual positive and negative effects of any creative action require learning how to balance risk appraisal with creative action.

Indeed, a variety of complexities likely will emerge during any creative endeavor, which can impact others, such as the nature of the novelty, the potential harm, the degree of betterment achieved, and political conditions. Sternberg and Chowcase [1] offer numerous examples from historical and present-day innovations to illustrate the subjective, valueladen process of balancing the positive and negative effects of creativity. The invention of the atomic bomb and improvements to nuclear-fission reactions serve as instructive examples. In the scientific community, nuclear fission is an important achievement and could further the development of efficient and safe nuclear energy. On the other hand, the role of nuclear weapons in political destabilization poses one of the most profound forms of human-created, existential threat to the world.

Although young people likely will not be engaged in projects that can threaten the future of humanity, it is still important for them to understand the responsibility to appraise 
risks in any creative endeavor and still have the confidence to take creative action on worthwhile endeavors. This includes developing an ethos aimed at serving "a common good by balancing the interests of all affected parties, over the long- as well as the shortterm, in a way that reflects positive ethical values" [1]. Educators can help young people assume the responsibility of learning how to strike a productive balance between systematic risk-appraisal and creative engagement. Teachers can use relatable examples, such as the benefits and drawbacks of the development of innovations such as social media, to help students learn how to weigh the potential benefits and hazards of developing creative and innovative products.

\section{Responsibility \#3: Taking Creative Action}

Identifying seemingly worthwhile and positive creative endeavors is only the first step; there is also a responsibility to bring positive outcomes into existence. Indeed, educators can help young people understand that principled creative endeavors ultimately require creative action. If young people, for instance, have a creative idea for how to address bullying of students in their school through social media, they have an ethical responsibility to put that idea into action. We recognize that there are barriers to doing so, including students' confidence in their ability to make such changes. It is thereby important that educators support the kinds of creative self-beliefs that can convert creative potential into creative action, which include everything from creative confidence, valuing creative action, and the willingness to take creative risks [6]. Unless students have developed these self-beliefs, it seems unlikely that they will creatively act when it is necessary to do so, particularly when social pressures are at play.

Teachers can play a key role in supporting adaptive and agentic creative self-beliefs, which starts with developing their own understanding of creativity and the willingness to infuse creative experiences in the curriculum [47]. For teachers to infuse creative learning opportunities in their own teaching requires a recognition that developing students' creative capacity is worthwhile and can be enhanced as part of the everyday learning experience. Researchers can also support this process by helping teachers and educational leaders assume this responsibility in their teaching $[15,48]$. Doing so can result in the establishment of a school environment that supports the students' sense of creative agency.

Supportive school environments can serve as what Bandura [13] has called proxy agency - a means for students to develop confidence in their own creative abilities through the modeling and support of teachers, administrations, and other students. When students see others valuing and engaging in principled creative efforts, they develop their own agency through vicarious learning [49], which can then increase the likelihood that students will engage in creative curricular experiences. Moreover, the benefits of creative engagement can also accrue to teachers and educational leaders in the form of feeling more interested, enthusiastic, relaxed, and emotionally engaged in their professional work [15].

Teachers' creative risk-taking in the classroom is a mixture of having confidence and valuing creativity as well as managing their own creative anxieties [50] when designing creative educational experiences for their students. Teachers have, for instance, described a variety of pressures and fears that contribute to their creative anxiety, including (a) perfectionism, (b) fear of making mistakes, (c) being judged by others as not creative, (d) being too old for creative achievement, and (e) not feeling talented enough [15]. Left unaddressed, these concerns can serve as a barrier to teacher engagement and persistence. Fortunately, when teachers become aware of their own fears, they can work to become more resilient in their efforts to infuse creative learning opportunities in their teaching.

When teachers become more aware of and actively work through their own fears and concerns, they can develop empathy for their students' creative risk-taking. Teachers who have developed this kind of creative empathy likely will be in a better position to support young people in taking creative risks. A principled approach to creativity thereby calls upon teachers to ensure that they are providing a structured and supportive learning environment while still encouraging students to take creative risks in their learning. 
Structuring creative uncertainties for young people by providing openings and support for students to engage in creative learning activities can go a long way in supporting students personal and collective agency for creative action. Research on students' resilience in other academic domains, for instance, indicates that anxiety is one of the greatest barriers [40]. Teachers' modeling, messaging, and structuring of teaching and learning can open up creative learning opportunities that shape students' agentic beliefs, which ultimately lead to creative action.

It is also important for students to value the collaborative nature of creative action. One way teachers can reinforce the importance of a collaborative creative approach in their students is to focus students' attention on the participatory aspects involved in creative endeavors. Clapp [51], for instance, describes how a participatory creative approach can help the young focus less on the biographies of singular creative geniuses and more on the biography of the creative ideas, which are shaped across time and include the involvement of many different people. A principled approach aligns with a participatory orientation to creative action, where all students can have the opportunity to acknowledge the contributions of others in their creative endeavors.

This participatory approach to creative action also increases the chances that students will welcome unique and different cultural and creative assets when engaging in creative educational projects. Indeed, a participatory approach actively welcomes and acknowledges the contributions of creative contributions of people who have otherwise been marginalized or ignored (e.g., African American Blues musicians by the white-dominant Rock and Roll music industry).

\section{Responsibility \#4: Systematically Evaluating Outcomes}

The fourth responsibility involves systematically monitoring and evaluating the outcomes of creative efforts. As has been discussed, creative action has both intended and unintended consequences. Even seemingly positive outcomes can, upon reflection, be recognized as having potentially negative side effects. A creative anti-bullying campaign might reduce the overt instances of bullying in a school but result in driving even more insidious forms of bullying on social media. Unless young people and educators systematically evaluate the outcomes of their efforts, deeper and more problematic consequences can outweigh short-term benefits. When this happens, people may become demoralized and come to believe that creative projects are not worth the time and effort.

The process of evaluating outcomes, therefore, is a responsibility that requires reflective and critical thinking capacities, which can be thought of as complementary to the openended and divergent aspects of creative thinking [1]. Indeed, because creative endeavors always involve engagement with some level of ambiguity [52] there is no way to fully anticipate all the possible outcomes that can result from taking creative action. This does not mean that creative action should be avoided, but rather that educators can help young people anticipate and proactively respond to unintended outcomes and side-effects of their creative efforts-viewing these emergent features as simply part of the broader creative process. When "failures" and unanticipated setbacks are viewed as inherent in the creative process [53], they can be transformed into active and creative learning opportunities, which lead to additional creative action. As young people learn that unintended outcomes are part of the creative process, they will be in a better position to also assume responsibility for evaluating the outcomes of their efforts and continuing to put forth creative effort to address potentially negative outcomes. It is in this way that the responsibility for systematically monitoring creative outcomes can "fertilize attitudes for positive creativity" [1], which includes developing the responsibility to ensure that young people develop their capacity to be compassionate, empathetic, and proactive in their efforts to make creative contributions to others. A principled approach to creativity is, therefore, as much about characterbuilding [7] as developing the capacity for creative action. 


\section{Examples of Educational Experiences That Promote Principled Creativity}

A few examples from the field can help illustrate how a principled approach to creativity takes shape for teachers and learners. For instance, the High Tech High Graduate School of Education's Center for Love and Justice uses six equity stances to guide the design of liberatory project-based learning [9]. The six stances align with the responsibilities outlined in this article; they are place, dialogue, democratization, liberation, belonging, and identity. The project Beyond the Crossfire (see https: / / www.hightechhigh.org/project/ beyond_the_crossfire/ 1 accessed on 1 March 2022) is among many project examples from High Tech High that showcase these equity stances and help to place the responsibilities of principled creativity in context.

Students at High Tech High Chula Vista in San Diego, CA, had experienced a shooting death of a fellow student on top of the numerous school shootings that had been occurring nationwide in recent years. They identified this issue as a creative opportunity that needed attention. Students appraised the risks in taking on this topic by learning about the polarizing nature of gun rights and gun control-they realized they would need to be careful to reach a broad audience with their research and message and not further polarize the dialogue on this contentious topic. Their creative action took the form of making a documentary film, including the launching of a Kickstarter campaign to fund the work. The Kickstarter campaign became a big creative action in itself, requiring a multimedia approach to increase the visibility of their aims and efforts. The students and teachers continuously adjusted their schedule, partnerships, and approach along the way to make sure they included representative voices from community members and families affected by gun violence and to understand and accurately portray some of the root causes of gun violence, such as untreated mental health issues. Students successfully created a documentary film that was selected for the San Diego Latino Film Festival. This example illustrates the importance of the sociocultural context, values, and experiences, which drive the purpose and passion behind students' creativity. The level of autonomy, belonging, and overall sense of agency needed for students to take a principled approach to creativity requires conditions that teachers can nurture with regular practice.

There are also efforts underway aimed at helping current and new generations of educators develop a more principled approach to creativity and innovation. The Principled Innovation (PI) initiative in the Mary Lou Fulton Teachers College at Arizona State University [find more information at https:/ /live-principled-innovation.ws.asu.edu/ accessed on 1 March 2022], for instance, focuses on helping current and future generations of educators and educational leaders develop their capacity to design and deliver equitable learning opportunities for all learners. This is accomplished by preparing educators to be innovative and ethical contributors now and into the future. The PI initiative infuses this core value in curricular and professional experiences of teacher preparation and educational leadership students. A principled approach to creativity is tightly aligned with many of the core practices of the PI initiative [7], including:

- identifying and acknowledging fundamental values,

- using moral and ethical decision-making,

- understanding culture and context,

- $\quad$ engaging multiple diverse perspectives,

- developing habits of an informed systems thinker,

- reflecting critically and compassionately,

- designing creative solutions, and

- navigating uncertainty and mitigating consequences.

The makeSPACE project (find more information at https:/ / www.makespaceproject. org / our-work/ accessed on 1 March 2022) is an example of another initiative aimed at helping teachers develop their own creative agency through personal experience in creative routines and the use of those routines in their work with students. These routines may be common, open-ended divergent thinking practices, such as thinking of alternative uses for an object or gestural play to represent new vocabulary words. This routine practice 
aims to cultivate the knowledge, skills, attitudes, and behaviors that undergird positive creativity [1]. Teachers involved in the makeSPACE project report are seeing increases in key aspects of principled creativity, including enhancing students' sense of belonging in class and a willingness to share their creative ideas and values with open minds and curiosity.

\section{Conclusions and Next Steps}

In this article, we have discussed how positive creativity in education requires taking a principled approach to identifying creative opportunities, appraising risks, taking action, and evaluating outcomes. Although taking a principled approach to creative endeavors can, at first blush, seem quite ambitious and even overwhelming, we hope that we have demonstrated that even small-scale projects can make meaningful contributions to the learning and lives of young people. As teachers and students develop their confidence working through small-scale projects, they can begin to realize how they can further extend their efforts by partnering with outside communities and experts to tackle increasingly complex challenges now and into the future. We also hope that educators can see how principled creative projects complement and extend academic learning by providing students with an opportunity to make positive contributions to their schools, communities, and beyond.

In closing, we want to underscore that there likely are many other examples of how educators and students have started to take a principled approach to creativity in K12 and higher education settings. We, therefore, invite researchers, educators, and anyone interested in moving positive creativity in education forward to join the effort. This can include everything from documenting and curating efforts they are involved in to supporting others in taking creative action. We hope that the principled approach to creativity in education that we have discussed herein can help such efforts by ensuring that current and future generations of young people have an opportunity to transform their creative potential into creative actions that make a positive and lasting contribution to the world around them.

Author Contributions: Both authors contributed to the conceptualization and writing of the paper. All authors have read and agreed to the published version of the manuscript.

Funding: This research received no external funding.

Institutional Review Board Statement: Not applicable.

Informed Consent Statement: Not Applicable.

Data Availability Statement: Not Applicable.

Conflicts of Interest: The authors declare no conflict of interest.

\section{References}

1. Sternberg, R.J.; Chowkase, A. When We Teach for Positive Creativity, What Exactly Do We Teach For? Educ. Sci. 2021, 11, 237. [CrossRef]

2. Schutte, N.S.; Malouff, J.M. Connections between curiosity, flow and creativity. Personal. Individ. Differ. 2020, 152, 109555. [CrossRef]

3. Amabile, T.M. Creativity in Context: Update to the Social Psychology of Creativity; Westview: Boulder, CO, USA, 1996.

4. Hennessey, B.A. Intrinsic motivation and creativity in the classroom: Have we come full circle? In Nurturing Creativity in the Classroom, 2nd ed.; Beghetto, R.A., Kaufman, J.C., Eds.; Cambridge University Press: New York, NY, USA, 2017.

5. Csikszentmihalyi, M. Flow and creativity. Namta J. 1997, 22, 60-97.

6. Beghetto, R.A.; Karwowski, M.; Reiter-Palmon, R. Intellectual Risk taking: A moderating link between creative confidence and creative behavior? Psychol. Aesthet. Creat. Arts 2021, 15, 637-644. [CrossRef]

7. Mary Lou Fulton Teachers College (MLFTC). Arizona State University. Principled Innovation in the Systems of Educator and Leader Preparation, 2nd ed.; 2019. Available online: https:/ / education.asu.edu/sites/default/files/framework-for-principled-innovation. pdf (accessed on 1 March 2022).

8. Moran, S. Ethical Ripples of Creativity and Innovation; Palgrave Macmillan: London, UK, 2016.

9. Rashad, K. The six equity stances of liberatory project-based learning. Unboxed: A J. Adult Learn. Sch. 2021, 21, 18-23. 
10. Kern, M.L.; Waters, L.E.; Adler, A.; White, M.A. A multidimensional approach to measuring well-being in students: Application of the PERMA framework. J. Posit. Psychol. 2015, 10, 262-271. [CrossRef]

11. White, M.; Kern, M.L. Positive education: Learning and teaching for wellbeing and academic mastery. Int. J. Wellbeing 2018, 8 , 1-17. [CrossRef]

12. Furlong, M.J.; Gilman, R.; Huebner, E.S. (Eds.) Handbook of Positive Psychology in Schools, 2nd ed.; Routledge: New York, NY, USA, 2014

13. Bandura, A. Exercise of human agency through collective efficacy. Curr. Dir. Psychol. Sci. 2000, 9, 75-78. [CrossRef]

14. Karwowski, M.; Beghetto, R.A. Creative behavior as agentic action. Psychol. Aesthet. Creat. Arts 2018, 13, 402-415. [CrossRef]

15. Anderson, R.C.; Katz-Buonincontro, J.; Bousselot, T.; Mattson, D.; Beard, N.; Land, J.; Livie, M. How am I a creative teacher? Beliefs, values, and affect for integrating creativity in the classroom. Teach. Teach. Educ. 2022, 110, 103583. [CrossRef]

16. Bereczki, E.O.; Kárpáti, A. Teachers' beliefs about creativity and its nurture: A systematic review of the recent research literature. Educ. Res. Rev. 2018, 23, 25-56. [CrossRef]

17. Katz-Buonincontro, J.; Perignat, E.; Hass, R.W. Conflicted epistemic beliefs about teaching for creativity. Think. Ski. Creat. 2020, 36, 100651. [CrossRef]

18. Anderson, R.C.; Porter, L.; Adkins, D. A Dramatic Confrontation of Frames: Arts-Integration Teacher Development, Organizational Learning, and School Change. Leadersh. Policy Sch. 2019, 19, 369-389. [CrossRef]

19. Brereton, P.; Kita, S. Exploring teacher creativity through duoethnography and reflection. Teach. Dev. Acad. J. 2020, 1, 7-19.

20. Karwowski, M.; Gralewski, J.; Patston, T.; Cropley, D.H.; Kaufman, J.C. The creative student in the eyes of a teacher: A cross-cultural study. Think. Ski. Creat. 2020, 35, 100636. [CrossRef]

21. Nagel, T. The View from Nowhere; Oxford University Press: London, UK, 1989.

22. Glăveanu, V.P.; Beghetto, R.A. Pedagogies of the possible. The Palgrave Encyclopedia of the Possible, Glăveanu, V.P., Ed.; Palgrave: London, UK, in press.

23. Harackiewicz, J.M.; Canning, E.A.; Tibbetts, Y.; Giffen, C.J.; Blair, S.S.; Rouse, D.I.; Hyde, J.S. Closing the social class achievement gap for first-generation students in undergraduate biology. J. Educ. Psychol. 2014, 106, 375-389. [CrossRef]

24. Diego, R.; Arias, J.M.; Sedlacek, Q.; Perez, G. Exploring conceptions of creativity and Latinidad in environmental education through the lens of culturally sustaining pedagogy. Rev. Res. Education. 2022.

25. Patton Davis, L.; Jenkins, T.; Howell, G.; Keith, A. Unapologetically Black creative educational experiences in higher education: A critical review. Rev. Res. Educ. 2022.

26. Hammond, Z. Culturally Responsive Teaching and the Brain; Corwin: Thousand Oaks, CA, USA, 2015.

27. Moje, E.; Ciechanowski, K.; Kramer, K.; Ellis, L.; Carrilo, R.; Collazo, T. Working toward third space in content area literacy: An examination of everyday funds of knowledge and discourse. Read. Res. Q. 2004, 39, 38-70. [CrossRef]

28. Hall, H.B. Deeper than rap: Expanding conceptions of hip-hop culture and pedagogy in the english language arts classroom. Res. Teach. Engl. 2017, 51, 341-350.

29. Emdin, C. For White Folks Who Teach in the Hood ... and the Rest of Ya'll too: Reality Pedagogy and Urban Education; Beacon Press: Boston, MA, USA, 2016.

30. Gray, D.L.L.; Hope, E.C.; Matthews, J.S. Black and belonging at school: A case for interpersonal, instructional, and institutional opportunity structures. Educ. Psychol. 2018, 53, 97-113. [CrossRef]

31. Getzels, J.W. Creative thinking, problem solving, and instruction. In Theories of Learning and Instruction; Hilgard, E.R., Ed.; University of Chicago Press: Chicago, IL, USA, 1964; pp. 240-267.

32. Pólya, G. On teaching problem solving. In Conference Board of the Mathematical Sciences, the Role of Axiomatics and Problem Solving in Mathematics; Ginn: Boston, MA, USA, 1966; pp. 123-129.

33. Pretz, J.E.; Naples, A.J.; Sternberg, R.J. Recognizing, defining, and representing problems. In The Psychology of Problem Solving; Davidson, J.E., Sternberg, R.J., Eds.; Cambridge University Press: New York, NY, USA, 2003; pp. 3-30.

34. Beghetto, R.A. Beautiful Risks: Having the Courage To Teach and Learn with Creativity; Rowman \& Littlefield: Lanham, MD, USA, 2019

35. Beghetto, R.A. Legacy projects: Helping young people respond productively to the challenges of a changing world. Roeper Rev. 2017, 39, 187-190. [CrossRef]

36. IDEO. Design Thing for Educators; IDEO: San Francisco, CA, USA, 2012.

37. Beghetto, R.A. There is no creativity without uncertainty: Dubito ergo creo. J. Creat. 2021, 31, 100005. [CrossRef]

38. Rose, D. Universal design for learning. J. Spec. Educ. Technol. 2000, 15, 45-49. [CrossRef]

39. Baert, P. Unintended consequences: A typology and examples. Int. Sociol. 1991, 6, 201-210. [CrossRef]

40. Anderson, R.C.; Haney, M.; Pitts, C.; Porter, L.; Bousselot, T. "Mistakes can be beautiful”: Creative engagement in arts integration for early adolescent learners. J. Creat. Behav. 2020, 54, 662-675. [CrossRef]

41. Jacovidis, J.N.; Anderson, R.C.; Beach, P.T.; Chadwick, K.L. Growth Mindset Thinking and Beliefs in Teaching and Learning; Inflexion: Eugene, OR, USA, 2020

42. Sternberg, R.J. Implicit theories of intelligence, creativity, and wisdom. J. Personal. Soc. Psychol. 1985, 49, 607-627. [CrossRef]

43. Sternberg, R.J.; Lubart, T.I. Defying the Crowd: Cultivating Creativity in a Culture of Conformity; Free press: New York, NY, USA, 1995.

44. Kaufman, J.C.; Beghetto, R.A. In praise of Clark Kent: Creative metacognition and the importance of teaching kids when (not) to be creative. Roep. Rev. 2013, 35, 155-165. [CrossRef] 
45. Hoffmann, J.D.; Ivcevic, Z.; Maliakkal, N. Emotions, creativity, and the arts: Evaluating a course for children. Empir. Stud. Arts 2020, 39, 123-148. [CrossRef]

46. Weisman, R. Gaviotas: A Village to Reinvent the World; Chelsea Green Publishing Company: Hartford, VT, USA, 1995.

47. Renzulli, J. Developing Creativity Across All Areas of the Curriculum. In Nurturing Creativity in the Classroom; Beghetto, R., Kaufman, J., Eds.; Cambridge University Press: Cambridge, UK, 2016; pp. 23-44. [CrossRef]

48. Kettler, T.; Lamb, K.N.; Willerson, A.; Mullet, D.R. Teachers' perceptions of creativity in the classroom. Creat. Res. J. 2018, 30, 164-171. [CrossRef]

49. Bandura, A. Social Foundations of Thought and Action; Prentice Hall: Englewood Cliffs, NJ, USA, 1968.

50. Daker, R.J.; Cortes, R.A.; Lyons, I.M.; Green, A.E. Creativity anxiety: Evidence for anxiety that is specific to creative thinking, from STEM to the arts. J. Exp. Psychol. Gen. 2019, 149, 42-57. [CrossRef] [PubMed]

51. Clapp, E. Participatory Research: Introducing Access and Equity to the Creative Classroom; Routledge: New York, NY, USA, 2016.

52. Furnham, A.; Marks, J. Tolerance for ambiguity: A review of the literature. Psychology 2013, 4, 717-728. [CrossRef]

53. Estabrooks, L.B.; Couch, S.R. Failure as an active agent in the development of creative and inventive mindsets. Think. Ski. Creat. 2018, 30, 103-115. [CrossRef] 